\title{
Association between daily TV time and physical fitness in 6- to 14-year-old Austrian youth
}

\author{
Klaus Greier ${ }^{1,2}$, Clemens Drenowatz ${ }^{3}$, Gerhard Ruedl ${ }^{1}$, Herbert Riechelmann ${ }^{4}$ \\ ${ }^{1}$ Department of Sport Science, University Innsbruck, Innsbruck, Austria; ${ }^{2}$ Division of Physical Education, Private University of Education (KPH- \\ ES), Stams, Austria; ${ }^{3}$ Division of Physical Education, University of Education Upper Austria, Linz, Austria; ${ }^{4}$ Department of Otolaryngology, Medical \\ University of Innsbruck, Innsbruck, Austria \\ Contributions: (I) Conception and design: K Greier; (II) Administrative support: K Greier; (III) Provision of study materials or patients: K Greier; (IV) \\ Collection and assembly of data: K Greier, G Ruedl; (V) Data analysis and interpretation: C Drenowatz, H Riechelmann; (VI) Manuscript writing: \\ All authors; (VII) Final approval of manuscript: All authors. \\ Correspondence to: Clemens Drenowatz. Division of Physical Education, University of Education Upper Austria, Kaplanhofstrasse 40, A-4020 Linz, \\ Austria. Email: clemens.drenowatz@ph-ooe.at.
}

\begin{abstract}
Background: Physical activity (PA) and sedentary behaviors have been associated with various health outcomes in youth, including overweight/obesity and physical fitness. Limited information, however, is available on the independent association between TV time and physical fitness in children and adolescents.

Methods: A total of 3,293 (55.1\% male) youth between 6 and 14 years of age were randomly selected from 29 Austrian schools. Body weight and height were measured according to standard procedures and BMI percentiles were determined based on German reference values. Physical fitness was assessed with the German Motor test (DMT6-18), which evaluates cardiorespiratory endurance, muscular strength, power, strength endurance, agility, speed and flexibility. Information on daily TV time and participation in club sports was obtained via standardized questionnaires.

Results: Participants were $9.8 \pm 2.3$ years of age and almost half of them $(48.5 \%)$ reported a TV time $>2$ hours/d. TV time increased significantly with age. High TV consumption was associated with significantly lower physical fitness and these results remained after adjusting for body weight. Youth exceeding current TV time recommendations had a $60 \%$ higher risk of having poor or very poor fitness compared to those with a TV time $<2$ hours/day.

Conclusions: High TV time is associated with poor physical fitness in youth. Accordingly, intervention strategies need to target a meaningful utilization of TV and other screen-based activities in addition to the promotion of PA in order to ensure sufficient physical fitness in youth.
\end{abstract}

Keywords: Screen time; sedentary behavior; motor competence; children; adolescents

Submitted Feb 01, 2019. Accepted for publication Mar 29, 2019.

doi: $10.21037 /$ tp.2019.03.03

View this article at: http://dx.doi.org/10.21037/tp.2019.03.03

\section{Introduction}

Beneficial effects of regular and sufficient physical activity (PA) in children and adolescents on general development, health and well-being have been well documented (1-3). Active and physically fit children are less likely to be overweight or obese, have a higher bone mineral density and display healthier cardiovascular profiles (4-6). Health benefits also depend on intensity and type of PA (1), with moderateto-vigorous PA (MVPA), providing largest benefits $(7,8)$.

With tremendous changes in the physical environment during the last decades, particularly in industrialized countries, youth are becoming increasingly more inactive (7-10). In addition to prolonged sitting times during school hours, a majority of children and adolescents engage in sedentary activities such as watching TV or 
playing computer games during their leisure time (11-13). Further, access to portable media (e.g., smartphones) has contributed to a rapid rise in screen time in youth (14). In light of this development, various studies have examined the negative consequences of high media consumption $(15,16)$. It has been shown that physical inactivity, particularly in connection with high screen time, is associated with overweight and obesity in youth (17), which increases the risk for various chronic diseases $(18,19)$. Already in the 1990 's it has been shown that youth who spend more than 5 hours per day in front of the TV have 3 times the risk for becoming obese compared to their peers who watch less than 2 hours per day (20). Subsequent research showed an association of excess screen time with compromised sleep duration and quality (21-23) as well as behavioral problems in children and adolescents (23-25).

In addition to a large number of youth exceeding current recommendations for screen time (26), many children and adolescents do not meet current PA recommendations of at least 60 minutes of MVPA per day $(8,27)$. Low levels of PA and high amounts of sedentary time also lead to an increasing number of children with poor physical fitness and motor competence (28-30). As time spent watching TV is predominantly a sedentary pursuit $(15,31)$, it can be speculated that TV time is independently associated with physical fitness and motor competence. The present study, therefore, examines the association between TV time and physical fitness in 6- to 14-year-old youth.

\section{Methods}

A total of 20 elementary schools (grades 1-4) and 14 middle schools (grades 5-8) from various districts in Western Austria were contacted regarding participation in the study. Two elementary schools and 4 middle schools declined to participate due to organizational problems resulting a final sample of 29 schools and a sample size of 3,293 (55.1\% male) students between 6 and 14 years of age. Data collection occurred between September 2015 and December 2017. Prior to any data collection parents received information about the study and provided written informed consent. Participants provided oral assent at the time of data collection. The study was approved by the respective school boards and the Institutional Review Board of the University of Innsbruck, Austria.

\section{Antbropometric measurements}

Body weight $(\mathrm{kg})$ and height $(\mathrm{cm})$ were measured according to standard procedures. Specifically, body weight was measured via an electronic scale (GRUNDIG ${ }^{\circledR} 3710$, Grundig AG, Germany) and height was measured with a portable stadiometer (SECA ${ }^{\circledR} 217$, Seca, Germany) with children being bare feet and wearing gym clothes to the nearest $0.1 \mathrm{~kg}$ and $0.1 \mathrm{~cm}$, respectively. Body mass index $(\mathrm{BMI})$ was calculated $\left(\mathrm{kg} / \mathrm{m}^{2}\right)$ and BMI percentiles were determined using German reference values (32). Subsequently, participants were classified as underweight ( $<10$ th percentile) normal weight (10th to 90 th percentile), overweight (90th to 97 th percentile) or obese ( $>97$ th percentile).

\section{Physical fitness}

Physical fitness was assessed with the German motor test (Deutscher Motorik Test, DMT6-18) (33) during regular opening hours of the school gym. The DMT6-18 is a standardized and validated test that consists of eight items: $20 \mathrm{~m}$ sprint, backwards balancing, sideways jumping, standing long jump, sit ups, pushups, stand-and-reach test and 6-minute run. Accordingly, it provides information on speed, balance, agility, power, muscular strength and strength endurance as well as cardiorespiratory endurance. Tests were administered in random order, except for the 6-minute run, which was performed at the end of the measurement session. In addition to raw performance scores age- and sex-standardized scores were calculated based on a German reference sample (33) and the average across all individual tests was used as an overall fitness score. Further, participants were classified into five physical performance categories (extremely poor, poor, average, good, very good) based on their performance on the respective test (33).

\section{Sedentary behavior and $P A$}

A standardized questionnaire was used to assess activity behaviors. Questionnaires were completed by the parents/ guardian for elementary school students while middleschool students reported the respective behaviors by themselves. In addition to the average daily TV time (hours/day) information on the presence of a TV in the participant's bedroom was obtained. Based on current recommendations for TV time of less than 2 hours/d (34) participants were stratified into low TV time ( $<2$ hours/d) and high TV time ( $>2$ hours/d). Participants also reported whether they were members in any sports club along with average weekly training time. 
Table 1 Height, weight and BMI percentile of study participants by age and sex

\begin{tabular}{|c|c|c|c|c|c|c|c|c|}
\hline Age (years) & \multicolumn{4}{|c|}{ Female } & \multicolumn{4}{|c|}{ Male } \\
\hline 6 & 132 & $121.9 \pm 6.2$ & $24.2 \pm 4.6$ & $57.7 \pm 27.0$ & 122 & $121.7 \pm 6.1$ & $24.0 \pm 4.8$ & $55.2 \pm 29.5$ \\
\hline 7 & 169 & $126.5 \pm 6.1$ & $26.4 \pm 5.5$ & $54.1 \pm 27.8$ & 185 & $126.8 \pm 6.5$ & $26.5 \pm 4.8$ & $56.6 \pm 28.3$ \\
\hline 8 & 164 & $130.5 \pm 6.5$ & $29.1 \pm 6.2$ & $55.8 \pm 28.1$ & 183 & $132.4 \pm 6.7$ & $30.5 \pm 6.5$ & $57.6 \pm 30.8$ \\
\hline 10 & 224 & $143.7 \pm 7.8$ & $38.0 \pm 9.2$ & $56.0 \pm 31.0$ & 318 & $144.5 \pm 7.3$ & $37.8 \pm 9.0$ & $55.1 \pm 30.4$ \\
\hline 11 & 276 & $149.9 \pm 7.7$ & $43.6 \pm 11.7$ & $57.8 \pm 31.5$ & 344 & $148.3 \pm 8.1$ & $41.0 \pm 10.3$ & $54.3 \pm 29.2$ \\
\hline 12 & 189 & $156.7 \pm 6.3$ & $49.9 \pm 12.2$ & $60.5 \pm 31.0$ & 270 & $156.3 \pm 7.9$ & $48.8 \pm 12.6$ & $59.1 \pm 30.4$ \\
\hline 13 & 106 & $160.1 \pm 6.0$ & $54.0 \pm 10.8$ & $63.5 \pm 28.1$ & 174 & $162.1 \pm 8.8$ & $54.1 \pm 14.0$ & $59.6 \pm 29.7$ \\
\hline
\end{tabular}

Values are mean \pm SD.

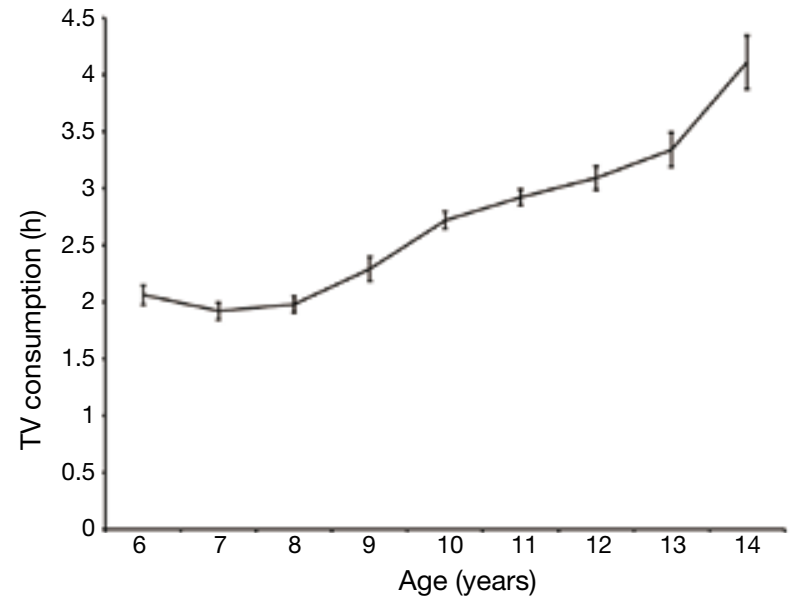

Figure 1 Daily TV consumption in hours per day (y-axis) as a function of age of study participants in years. The bars correspond to the $95 \%$ confidence intervals.

\section{Statistical analysis}

For interval-scaled data, mean and standard deviation (SD) were calculated and for ordinal variables frequencies were tabulated. Group comparisons were made with the Kruskal-Wallis and the Mann-Whitney U test, respectively, due to data distribution and ceiling effects. Relationships of temporal trends were tested with the JonckheereTerpstra test. The impact of TV consumption and BMI percentile on motor performance was assessed with multifactorial analysis of variance considering interaction effects. Relationships of ordinal variables were tested with the chi-square test. Odds ratios and $95 \%$ confidence intervals were calculated to examine the association between fitness categories and TV time. The level of significance was set at $\mathrm{P} \leq 0.05$. Statistical processing and analysis of the collected data was done with the statistics program SPSS, version 24 (IBM, Armonk, NY, USA).

\section{Results}

Valid data was provided by 3,293 children and adolescents with an average age of $9.8 \pm 2.3$ years. Average body weight was $39.1 \pm 13.9 \mathrm{~kg}$ and average height was $143.7 \pm 14.7 \mathrm{~cm}$, resulting in an average BMI percentile of $57.4 \pm 29.8$. The prevalence of overweight/obesity was $19.5 \%$ with no difference between boys and girls. There was, however, a significant increase in the prevalence of overweight/obesity with increasing age $(13.6 \%$ at 6 years to $28.6 \%$ at 14 years, $\mathrm{P}<0.01)$. Descriptive characteristics by age group and separately for males and females are displayed in Table 1 .

Average TV time was $2.7 \pm 1.1$ hours/d with $48.5 \%$ reporting more than 2 hours/d. Girls reported significantly lower TV time (2.6 \pm 1.1 hours/d) compared to boys $(2.8 \pm 1.1$, $\mathrm{P}<0.01)$. TV time increased significantly with age from $2.1 \pm 0.7$ hours $/ \mathrm{d}$ at the age of 6 to $4.1 \pm 1.5$ hours $/ \mathrm{d}$ at the age of 14 (Figure 1). Further, $52.6 \%$ had a TV in their bedroom and TV time was significantly higher in participants having a TV in their room compared to those who did not $(3.1 \pm 1.2$ vs. $2.3 \pm 1.2$ hours/d, $\mathrm{P}<0.01)$. Club sports participation was reported by $48.5 \%$ of the participants ( $41 \%$ of girls, $59 \%$ of boys) and participation in club sports was associated with 


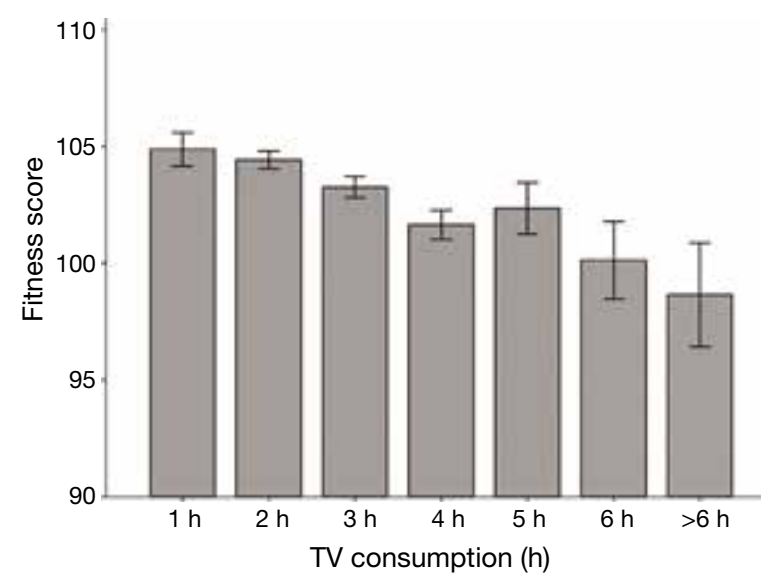

Figure 2 Z-score for physical fitness according to Bös et al. [2009] (y-axis) and daily TV consumption of study participants in hours (x-axis). The bars correspond to the $95 \%$ confidence interval.

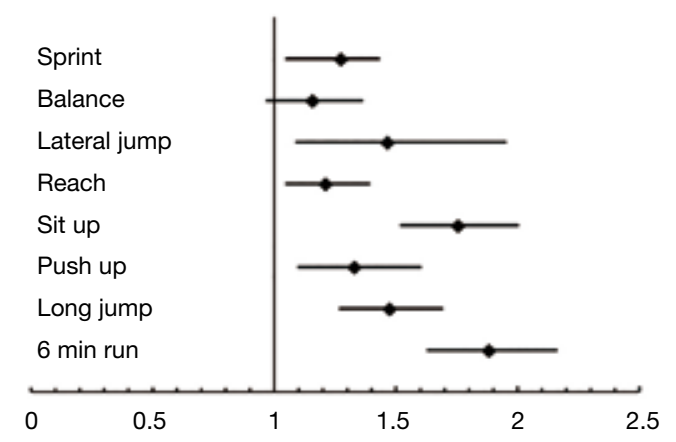

Figure 3 Odds ratios (x-axis) for poor performance in 8 physical fitness test (y-axis) by $>2$ hours TV-time per day in 3,293 youth aged 6 to 14 years. Bars indicate $95 \%$ confidence intervals. Overall, poor performance in total fitness scores was 1.6 (95\% CI: 1.4-1.9) times more likely in children watching more than 2 hours TV per day.

significantly lower TV time $(\mathrm{P}<0.01)$.

A total physical fitness score of $103.6 \pm 7.0$ indicates slightly above average physical fitness in the total sample. Nevertheless, $20 \%$ of the participants displayed poor or very poor physical fitness. TV time was significantly associated with physical fitness $(\mathrm{P}<0.01)$. Youth watching $\mathrm{TV}$ for less than 1 hour/d had a fitness score of $104.9 \pm 6.6$, while the fitness score of those watching more than 6 hours/d was $98.7 \pm 4.7$ (Figure 2). Children and adolescents exceeding current recommendations of 2 hours/d further showed a $60 \%$ increased risk of having poor or very poor fitness compared to those meeting current recommendations for screen time (odds ratio $=1.6 ; 95 \%$ CI: $1.4-1.9$ ). The odds ratios for poor performance in the 8 test items in children watching more than 2 hours TV per day are depicted in Figure 3.

Additionally, high TV time was associated with a $50 \%$ increased risk for being overweight/obese compared to those with lower TV time (odds ratio $=1.5$; 95 CI: $1.3-1.8$ ). Nevertheless, the associations between TV time and physical fitness remained significant after adjustment for BMI percentile in a multifactorial model $(\mathrm{P}<0.001)$.

\section{Discussion}

Several studies have shown a decline in physical fitness in youth over the last several decades (29,35-37). This can, at least partially, be attributed to declines in PA and increased body weight in children and adolescents (38-40). Further, sedentary pursuits such as watching TV or playing computer games have become popular leisure choices in youth (12). The increasing amount of daily TV time has also been associated with an increase in the prevalence of overweight and obesity in youth (41). Limited information, however, is available on the association between TV time and physical fitness, independent of body weight. Given that high TV time most likely increases total sedentary time a direct link towards impaired physical fitness is plausible. The aim of the present study, therefore, was to examine the association between daily TV consumption on physical fitness in children and adolescents after adjusting for body weight.

Results of the present study show that youth spend a considerable time watching TV and that TV time increases with increasing age. Almost half of the participants reported TV time above the current recommendations of 2 hours/d and more than half of the participants had a TV in their bedroom. Having a TV in the bedroom was also associated with higher TV time. This is of particular concern as high TV time has been associated with increased chronic disease risk during childhood, adolescence and adulthood $(42,43)$. Further, participants reporting higher TV time spent less time in club sports, which may indicate a lower engagement in overall PA. Data from the Health Behavior in School aged Children (HBSC) study also showed an inverse association between TV time and PA (44).

Consistent with previous research there was an inverse association between TV time and physical fitness $(12,45,46)$. Of note, however, was that the negative association between TV time and physical fitness was independent of body weight. This may, at least partially, be attributed to the 
previously addressed inverse association between TV time and PA. In addition, excess TV time has been associated with impaired quality and quantity of sleep $(21-23,47)$. Lack of sufficient sleep results in greater tiredness throughout the day $(48,49)$, which potentially affects the motivation towards and active engagement in PA (50). Particularly at young ages, a wide variety of movement experiences, however, is important for the development of motor competence and physical fitness, which forms the foundation of participation in PA and sports later in life (51). Accordingly, physical fitness is considered a key component in the promotion of an active lifestyle throughout adolescence and into adulthood.

Given the detrimental effects of TV time on youth's development and well-being it is necessary to educate children, adolescents and their caregivers on a proper and meaningful utilization of available media. Adolescents with set rules regarding TV and video games sleep about 30 minutes more per night and set rules about smartphones were associated with almost 20 minutes more sleep per night compared to those with no rules (52). The fact that sedentary behavior tracks from childhood throughout adolescence into adulthood $(53,54)$ further emphasizes the importance of early intervention. Schools may provide a viable setting as they allow reaching a large number of children and adolescents, independent of their socio-economic status. Further, schools allow for an implementation of various intervention strategies at different age groups using appropriate materials. Nevertheless, parents or caregivers need to be involved as well as many forms of electronic media are predominantly used during leisure time. The utilization of sports clubs may facilitate parental involvement in regulating media time, while promoting PA. The efficacy of intervention strategies, particularly when targeting physical fitness, may generally be improved when PA and sedentary behaviors are addressed together.

Several limitations of this study, however, need to be considered when interpreting the results. Due to the crosssectional design, a causal relationship between TV time and physical fitness cannot be established. Most likely, there is a bi-directional relationship as has been shown for the association between body weight and physical fitness (39). Further, objective information on total PA or sedentary behavior was not obtained and TV time was assessed via self-report. Physical fitness, on the other hand, has been directly measured. The utilization of a widely-used and validated test-battery along with the large sample size is a considerable strength of this study as several other largescale studies, such as the health-behavior of school-children survey (HBSC), assessed physical fitness via questionnaire only. The large age range, covering a critical period in human development and the establishment of lifestyle patterns should also be considered a strength of this study.

Overall, results of this study indicate that a majority of children and adolescents exceed the currently recommended TV time of 2 hours/day. Previous research showed an association of high TV time with increased body weight and cardiometabolic risk, reduced quality and quantity of sleep and lower PA $(22,55)$. Of additional concern is the inverse association of TV time with motor development and physical fitness as this is an important contributor to a sustainable healthy lifestyle. Accordingly, intervention strategies need to target sedentary behaviors such as watching TV in addition to promoting PA and physical fitness in children and adolescents. As sedentary behaviors have been shown to track over time (56), intervention programs should be implemented early in life. While schools may be the most prominent setting for intervention programs targeting health behavior in youth, sports club may provide a viable option as well due to potentially increased peer support and stronger parental involvement. Beneficial effects of club sports participation on physical fitness may further help with limiting sedentary behaviors as children and adolescents with higher fitness levels may be more likely to select active leisure behaviors.

\section{Acknowledgments}

None.

\section{Footnote}

Conflicts of Interest: The authors have no conflicts of interest to declare.

\section{References}

1. Janssen I, Leblanc AG. Systematic review of the health benefits of physical activity and fitness in school-aged children and youth. Int J Behav Nutr Phys Act 2010;7:40.

2. Annesi JJ. Correlations of depression and total mood disturbance with physical activity and self-concept in preadolescents enrolled in an after-school exercise program. Psychol Rep 2005;96:891-8.

3. Brosnahan J, Steffen LM, Lytle L, et al. The relation 
between physical activity and mental health among Hispanic and non-Hispanic white adolescents. Arch Pediatr Adolesc Med 2004;158:818-23.

4. Biddle SJ, Gorely T, Stensel D. Health-enhancing physical activity and sedentary behaviour in children in adolescents. J Sports Sci 2004;22:679-701.

5. Boreham CA, McKay HA. Physical activity in childhood and bone health. Br J Sports Med 2011;45:877-9.

6. Hallal PC, Victora CG, Azevedo MR, et al. Adolescent physical activity and health: a systematic review. Sports Med 2006;36:1019-30.

7. Strong WB, Malina RM, Blimkie CJ, et al. Evidence based physical activity for school-age youth. J Pediatr 2005;146:732-7.

8. World Health Organization. Health Behavior in Schoolaged children (HBSC) Study: International Report from the 2013/2014 Survey. Copenhagen: WHO Regional Office for Europe, 2016.

9. Dollman J, Norton K, Norton L. Evidence for secular trends in children's physical activity behaviour. Br J Sports Med 2005;39:892-7; discussion 897.

10. Hills AP, King NA, Armstrong TP. The contribution of physical activity and sedentary behaviours to the growth and development of children and adolescents: implications for overweight and obesity. Sports Med 2007;37:533-45.

11. Biddle SJ, Gorely T, Marshall SJ, et al. The prevalence of sedentary behavior and physical activity in leisure time: A study of Scottish adolescents using ecological momentary assessment. Prev Med 2009;48:151-5.

12. Kaiser-Jovy S, Scheu A, Greier K. Media use, sports activities, and motor fitness in childhood and adolescence. Wien Klin Wochenschr 2017;129:464-71.

13. Mathers M, Canterford L, Olds T, et al. Electronic media use and adolescent health and well-being: cross-sectional community study. Acad Pediatr 2009;9:307-14.

14. Pea R, Nass C, Meheula L, et al. Media use, face-toface communication, media multitasking, and social well-being among 8- to 12-year-old girls. Dev Psychol 2012;48:327-36.

15. Borghese MM, Tremblay MS, Leduc G, et al. Independent and combined associations of total sedentary time and television viewing time with food intake patterns of 9- to 11-year-old Canadian children. Appl Physiol Nutr Metab 2014;39:937-43.

16. Dutra GF, Kaufmann CC, Pretto AD, et al. Television viewing habits and their influence on physical activity and childhood overweight. J Pediatr (Rio J) 2015;91:346-51.

17. Braithwaite I, Stewart AW, Hancox RJ, et al. The worldwide association between television viewing and obesity in children and adolescents: cross sectional study. PLoS One 2013;8:e74263.

18. Gabel L, Ridgers ND, Della Gatta PA, et al. Associations of sedentary time patterns and TV viewing time with inflammatory and endothelial function biomarkers in children. Pediatr Obes 2016;11:194-201.

19. Jiménez-Pavón D, Konstabel K, Bergman P, et al. Physical activity and clustered cardiovascular disease risk factors in young children: a cross-sectional study (the IDEFICS study). BMC Med 2013;11:172.

20. Gortmaker SL, Must A, Sobol AM, et al. Television viewing as a cause of increasing obesity among children in the United States, 1986-1990. Arch Pediatr Adolesc Med 1996;150:356-62.

21. Cain N, Gradisar M. Electronic media use and sleep in school-aged children and adolescents: A review. Sleep Med 2010;11:735-42.

22. Hale L, Guan S. Screen time and sleep among school-aged children and adolescents: a systematic literature review. Sleep Med Rev 2015;21:50-8.

23. Parent J, Sanders W, Forehand R. Youth Screen Time and Behavioral Health Problems: The Role of Sleep Duration and Disturbances. J Dev Behav Pediatr 2016;37:277-84.

24. Kremer P, Elshaug C, Leslie E, et al. Physical activity, leisure-time screen use and depression among children and young adolescents. J Sci Med Sport 2014;17:183-7.

25. Page AS, Cooper AR, Griew P, et al. Children's screen viewing is related to psychological difficulties irrespective of physical activity. Pediatrics 2010;126:e1011-7.

26. Rideout V, Foehr U, Roberts D. Generation M2: Media in the lives of 8- to 18-year olds. Menlo Park, CA: Kaiser Family Foundation; 2010.

27. Reilly JJ, Jackson DM, Montgomery C, et al. Total energy expenditure and physical activity in young Scottish children: mixed longitudinal study. Lancet 2004;363:211-2.

28. Tomkinson GR, Léger LA, Olds TS, et al. Secular trends in the performance of children and adolescents (19802000): an analysis of 55 studies of the $20 \mathrm{~m}$ shuttle run test in 11 countries. Sports Med 2003;33:285-300.

29. Tomkinson GR, Olds TS. Secular changes in pediatric aerobic fitness test performance: the global picture. Med Sport Sci 2007;50:46-66.

30. Hardy LL, Reinten-Reynolds T, Espinel P, et al. Prevalence and correlates of low fundamental movement skill competency in children. Pediatrics 2012;130:e390-8.

31. Robinson TN. Television viewing and childhood obesity. 
Pediatr Clin North Am 2001;48:1017-25.

32. Kromeyer-Hauschild K, Wabitsch M, Kunze D, et al. Perzentile für den Body-mass-Index für das Kindesund Jugendalter unter Heranziehung verschiedener deutscher Stichproben. Monatsschrift Kinderheilkunde 2001;149:807-18.

33. Bös K, Schlenker L, Büsch D, et al. Deutscher MotorikTest 6-18 (DMT6-18) [German motor abilities test 6-18 (DMT6-18)]. Hamburg, Germany: Czwalina, 2009.

34. Education AAoPCoP. American Academy of Pediatrics: Children, adolescents, and television. Pediatrics 2001;107:423-6.

35. Albon HM, Hamlin MJ, Ross JJ. Secular trends and distributional changes in health and fitness performance variables of 10-14-year-old children in New Zealand between 1991 and 2003. Br J Sports Med 2010;44:263-9.

36. Runhaar J, Collard DC, Singh AS, et al. Motor fitness in Dutch youth: differences over a 26-year period (19802006). J Sci Med Sport 2010;13:323-8.

37. Sandercock G, Voss C, McConnell D, et al. Ten year secular declines in the cardiorespiratory fitness of affluent English children are largely independent of changes in body mass index. Arch Dis Child 2010;95:46-7.

38. Freedman DS, Goodman A, Contreras OA, et al. Secular trends in $\mathrm{BMI}$ and blood pressure among children and adolescents: the Bogalusa Heart Study. Pediatrics 2012;130:e159-66.

39. Greier K, Drenowatz C. Bidirectional association between weight status and motor skills in adolescents : A 4-year longitudinal study. Wien Klin Wochenschr 2018;130:314-20.

40. Sigmundová D, El Ansari W, Sigmund E, et al. Secular trends: a ten-year comparison of the amount and type of physical activity and inactivity of random samples of adolescents in the Czech Republic. BMC Public Health 2011;11:731.

41. Robinson TN, Banda JA, Hale L, et al. Screen Media Exposure and Obesity in Children and Adolescents. Pediatrics 2017;140:S97-S101.

42. Grøntved A, Ried-Larsen M, Møller NC, et al. Youth screen-time behaviour is associated with cardiovascular risk in young adulthood: the European Youth Heart Study. Eur J Prev Cardiol 2014;21:49-56.

43. Ekelund U, Brage S, Froberg K, et al. TV viewing and physical activity are independently associated with metabolic risk in children: the European Youth Heart Study. PLoS Med 2006;3:e488.

44. Iannotti RJ, Kogan MD, Janssen I, et al. Patterns of adolescent physical activity, screen-based media use, and positive and negative health indicators in the U.S. and Canada. J Adolesc Health 2009;44:493-9.

45. Barker AR, Gracia-Marco L, Ruiz JR, et al. Physical activity, sedentary time, TV viewing, physical fitness and cardiovascular disease risk in adolescents: The HELENA study. Int J Cardiol 2018;254:303-9.

46. Edelson LR, Mathias KC, Fulgoni VL, et al. Screenbased sedentary behavior and associations with functional strength in 6-15 year-old children in the United States. BMC Public Health 2016;16:116.

47. Fobian AD, Avis K, Schwebel DC. Impact of Media Use on Adolescent Sleep Efficiency. J Dev Behav Pediatr 2016;37:9-14.

48. Li S, Jin X, Wu S, et al. The impact of media use on sleep patterns and sleep disorders among school-aged children in China. Sleep 2007;30:361-7.

49. van den Bulck J. Is television bad for your health? Behavior and body image of the adolescent 'Couch Potato'. J Youth Adol 2000;29:273-88.

50. Biddle SJH, Pearson N, Salmon J. Sedentary Behaviors and Adiposity in Young People: Causality and Conceptual Model. Exerc Sport Sci Rev 2018;46:18-25.

51. Stodden D, Goodway J, Langendorfer S, et al. A developmental perspective on the role of motor skill competence in physical activity: an emergent relationship. Quest 2008;60:290-306.

52. Foundation NS. 2014 Sleep in America Poll: Sleep in the Modern Family. Washington, DC: The Foundation, 2014.

53. Francis SL, Stancel MJ, Sernulka-George FD, et al. Tracking of TV and video gaming during childhood: Iowa Bone Development Study. Int J Behav Nutr Phys Act 2011;8:100.

54. Telama R. Tracking of physical activity from childhood to adulthood: a review. Obes Facts 2009;2:187-95.

55. Carson V, Hunter S, Kuzik N, et al. Systematic review of sedentary behaviour and health indicators in school-aged children and youth: an update. Appl Physiol Nutr Metab 2016;41:S240-65.

56. Biddle SJ, Pearson N, Ross GM, et al. Tracking of sedentary behaviours of young people: a systematic review. Prev Med 2010;51:345-51.

Cite this article as: Greier K, Drenowatz C, Ruedl G, Riechelmann H. Association between daily TV time and physical fitness in 6- to 14-year-old Austrian youth. Transl Pediatr 2019;8(5):371-377. doi: 10.21037/tp.2019.03.03 